\title{
REGENERAGE® Cream Anti-aging Effect in Women
}

\author{
Joel I Osorio ${ }^{1 *}$, Geannyne Villegas ${ }^{2}$, Lejla R Stojanovic ${ }^{3}$ and Sergei Paylian ${ }^{4}$
}

${ }^{1}$ Regenerage International, USA

${ }^{2}$ Universidad de Guadalajara, Mexico

${ }^{3}$ Regenerage Europe, Serbia

${ }^{4} \mathrm{PhD}$ Bioquark Inc, USA

Submission: March 17, 2020; Published: April 03, 2020

*Corresponding author: Joel I Osorio, Regenerage International, USA

Summary

Introduction: The skin aging, in addition to the general guideline of the whole organism, is negatively influenced by various internal and external factors that can accelerate and modify it. There are several anti-aging therapies, including those for topical use with greater acceptance among users. Bioquantine $®$ is an innovative product with regenerative properties that has been added to REGENERAGE® cream.

Objective: To evaluate the REGENERAGE® cream anti-aging effect in 12 women.

Material and Methods: Exploratory clinical trial, randomized, double-blind, placebo-controlled parallel group. Ten healthy volunteers with a diagnosis of facial photo-aging were included. They were randomly assigned to the REGENERAGE $®$ cream in half of the face and placebo cream in the other; The study products were applied every day in the morning and evening, for 12 weeks. Baseline evaluations were carried out in week 6 and 12 of: the surface of the living skin (SELS, Surface Evaluation of Living Skin) with the VISIA equipment, clinical scales, as well as irritation and safety parameters (Figure 1).
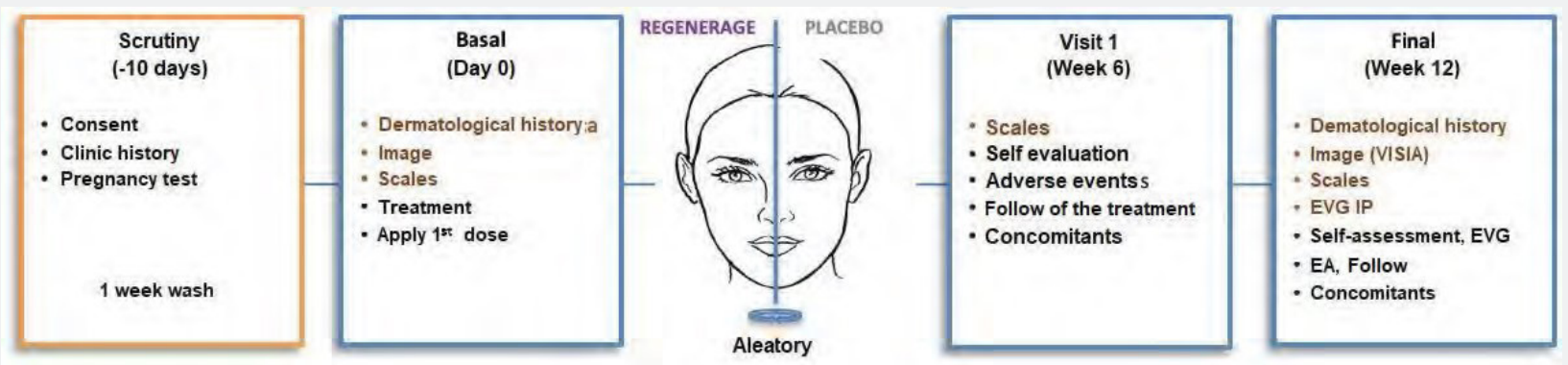

Figure 1: General outline of study visits.

Results: The patients had an average age of $44 \pm 3.9$ years. The surface parameters of living skin: superficial spots, wrinkles, texture, pores, deep spots, redness and porphyrins, showed no statistically significant differences at 12 weeks with respect to the baseline; in addition, no differences were observed between groups. The UV spots parameter had an average improvement after 12 weeks of $17 \%$ in the REGENERAGE® group and $24 \%$ in the placebo group, $\mathrm{p}<0.05$; No differences were observed between the groups. In irritation symptoms: 1 patient reported redness, other pimples and in 2 cases of skin burning when the study product is applied; all of mild intensity. The overall satisfaction of the subresearcher was: "regular" 50\% (n=5), "good" 40\% (n=4) and "bad" $10 \%(n=1)$. The overall satisfaction of the study products by the patients was: "good" 50\% (n=5), "very good" 40\% (n=4) and "excelent" 10\% (n=1). There were no adverse events.

\section{Introduction}

The decrease in mortality and the consequent increase in life expectancy, contributes to more people surviving to advanced ages, which increases the size of the cohorts that move along the successive steps of the age pyramid [1]. Unlike the chronological aging that can be studied by intrinsic biological processes, the skin is influenced by external factors such as sun exposure and environmental pollution that affect it negatively [2]. Over the 
years, physical attractiveness and social status are strongly correlated, since in our society a youth aspect confers economic and social advantages [3]. Anti-aging medicine is as old as the history of mankind. From the first civilizations there is evidence of a constant search to find a "potion" so as not to grow old. In ancient Egypt, olive leaves were used to increase beauty and extend life, while Ayurvedic medicine in India developed diets, lifestyle changes and specific herbs for the same purpose [4]. It is clear that topical treatment with cosmetics can help improve facial aging problems, in particular, by improving pigmentation, general skin tone, surface roughness, fine and deep wrinkles, diffuse redness and stains [5]. Based on what was previously described, the present study was carried out to evaluate the anti- aging effect and safety of the REGENERAGE ${ }^{\circledR}$ cream, which contains Bioquantine $^{\circledR}$ as the active substance.

\section{Participants}

Mexican women over 18, residents of Jalisco, were invited to participate in the study with diagnoses of facial aging. Patients were included who voluntarily agreed to participate in the study by granting the signature of informed consent, clinically healthy, with a Fitzpatrick's I-IV phototype and at least 2 points deep in the surface wrinkles on the Griffiths scale. Likewise, they should be outpatients, with a negative pregnancy test and because of the nature of the study, they should be able to read, write and complete questionnaires. Pregnant or lactating women were not included, those who had no contraceptive method; were in treatment with other products or anti-aging therapies 6 months prior to the start of the study (antioxidants, botulinum toxin fillers, laser therapies, firming or facial therapies and/or neck with energy-based equipment). Nor those with use of Cosmetics with anti-aging products at least 2 weeks prior to the start of treatment (antioxidants, retinol, retinoids, alpha hydroxy acid, peptides, growth factors) Administration of hormonal contraceptives, autoimmune diseases, history of chronic skin allergies, skin cancer, or rosacea, as well as active lesions at the site of application, hypersensitivity to the study products, atopic dermatitis and chronic degenerative diseases such as type 2 diabetes mellitus, systemic arterial hypertension, renal insufficiency or a history of smoking [6].

Visits and procedures: In general, the study was divided into 4 visits, in which the clinical and photographic evaluations of the patients were carried out.

Informed consent: All procedures and study requirements were explained to the patients before any intervention. The signature of the participants and two witnesses was obtained. A copy was delivered to the participants.

Internal code: All patients were assigned an internal personal identification number to guarantee confidentiality throughout the study, for logistic aspects, as well as for the analysis of the information. Eg PEC-19.001.

Clinic history: A medical history was developed based on NOM-004-SSA3-20126. Likewise, we inquired about previous diagnoses, treatments, allergies and hypersensitivity to the products in the study.

Vital signs: Seating blood pressure, heart rate, respiratory rate and body temperature were evaluated.

Pregnancy test: Patients were asked to grant a urine sample in a plastic container and the presence of chorionic gonadrotropin was determined by a rapid test [7].

Review of inclusion and exclusion criteria: With the activities carried out during the visit, the decision was made to invite the patients to participate in the research protocol.

Dermatological clinical history: A detailed dermatological medical history was developed that included physical examination of the skin with emphasis on the region of the face and neck.

Clinical scales of photoaging: The clinical signs of facial skin photo-aging were evaluated according to the scales (Table 1).

Table 1: Glogau scale.

\begin{tabular}{|c|c|}
\hline Type I: wrinkle free & Type III: resting wrinkles \\
\hline - Early photoaging & - Advanced photoaging \\
\hline - Medium pigmentary changes & - Obvious dyschromia, telangiectasia \\
\hline - Without keratosis & - visible keratosis \\
\hline - Minimum wrinkles & - Wrinkles visible even without movement \\
\hline - Age between 20 and 30 years & - Age over 50 years \\
\hline - Without makeup or at a minimum $\bullet$ Minimal acne healed & $\begin{array}{c}\text { - Use of compact base } \cdot \text { Prensence of acne scars that do not cover } \\
\text { makeup }\end{array}$ \\
\hline Type II: wrinkles with movement & Type IV (severe): wrinkles only \\
\hline - Early to moderate photoaging & - Severe photoaging \\
\hline - Senile lentigo visible early & - Early malignant skin lesions \\
\hline - Palpable keratosis but not visible & - Wrinkles all over the face \\
\hline $\begin{array}{l}\text { - Lines parallel to the smile begin to appear } \bullet \text { Age between } 30 \text { and } 40 \\
\text { years }\end{array}$ & - There are no areas of normal skin $\bullet$ Age between 60 and 70 years \\
\hline
\end{tabular}




\begin{tabular}{|c|c|}
\hline$\bullet$ Use of some makeup base & $\bullet$ Makeup: cannot be used \\
\hline$\bullet$ Acne scars tights & $\bullet$ Severe acne scars \\
\hline
\end{tabular}

Digital photographic record: Digital photographs of the face (Canfield Scientific, Fairfield, NJ, USA) in three projections: right, were taken with the VISIA equipment (VISIA Complexion Analysis left and frontal oblique (Figure 2).

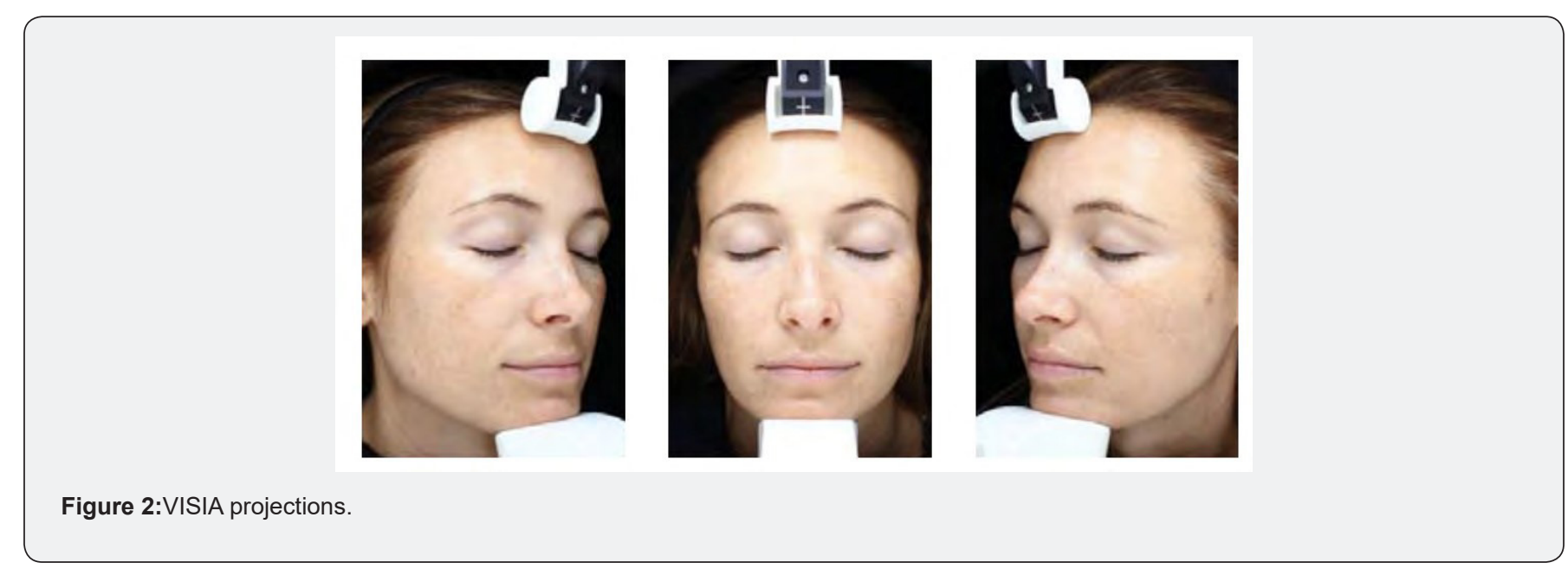

Review inclusion and exclusion criteria: With the activities carried out in this visit, the decision was made to randomize the patients.

Assignment study code: A unique study code was awarded to each patient with which all the information generated during their participation in the study was identified. Example: REG-001. Likewise, this code corresponded to the randomization of the treatment received.

Deliver study products: According to the unique identification code, 2 packages were delivered: one marked with the legend "1Right" and another with "2-Left", which by the randomization process could contain either of the two study treatments (Table 2) (Figure 3).

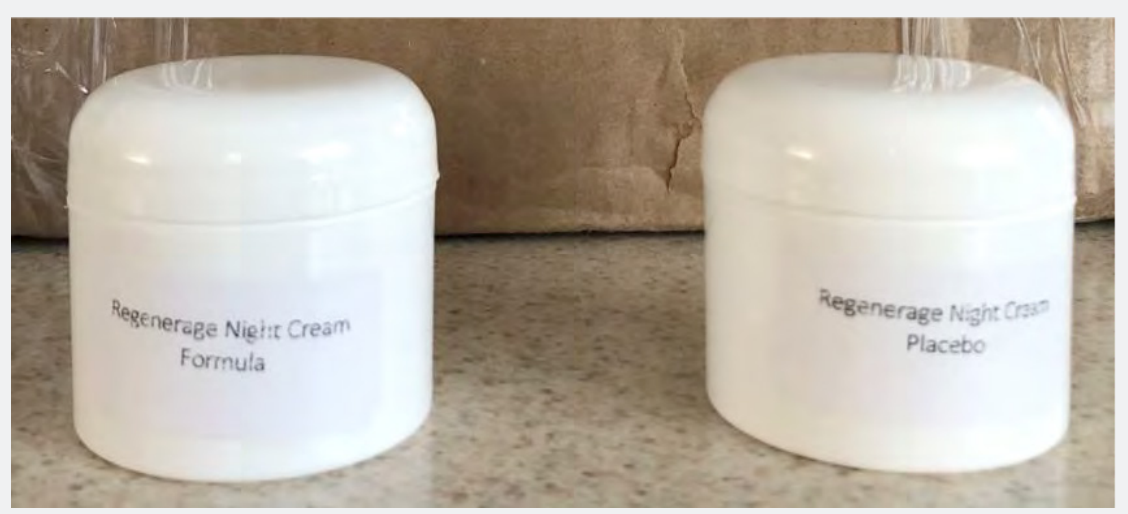

Figure 3:Study products .

First dose application of medication: The correct way of applying the study products was explained and doubts were resolved. The first dose was applied in the office (Figure 4).

Daily Patient Delivery: A diary was delivered where they should record every day: date, time of application, symptoms or signs of irritation, adverse events, as well as medications or concomitant therapies.
Schedule the appointment week 6: After carrying out the activities of this visit the next one, corresponding to week 6 , was schedule. Follow-up activities. Vital signs were taken, inquired about the presence of adverse events, concomitant medications, study deviations and accounting of the study products.

Survey of irritation: Patients were questioned about symptoms of irritation with the study products. 


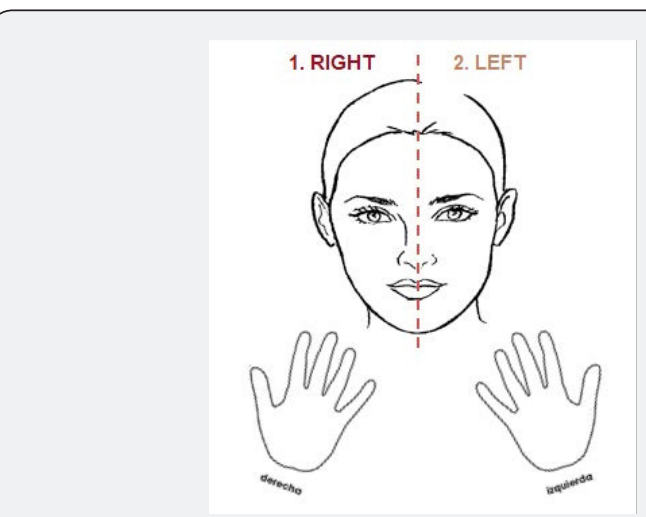

Figure 4: Application of study products.
Daily Patient Delivery: When no elimination criteria were presented, the patient's second diary was delivered and the appointment was scheduled for week 12 .

Overall satisfaction survey for patients: Additionally, the patients answered the satisfaction survey of the study products.

Global satisfaction survey for sub-researcher: After the clinical and photographic evaluation of the patients, the subresearcher answered the satisfaction survey of the study products. Patients were graded for their participation in the study, an original sample of the REGENERAGE ${ }^{\circledR}$ cream was delivered and it was recommended to continue with the sun protection measures [8] (Figure 5).

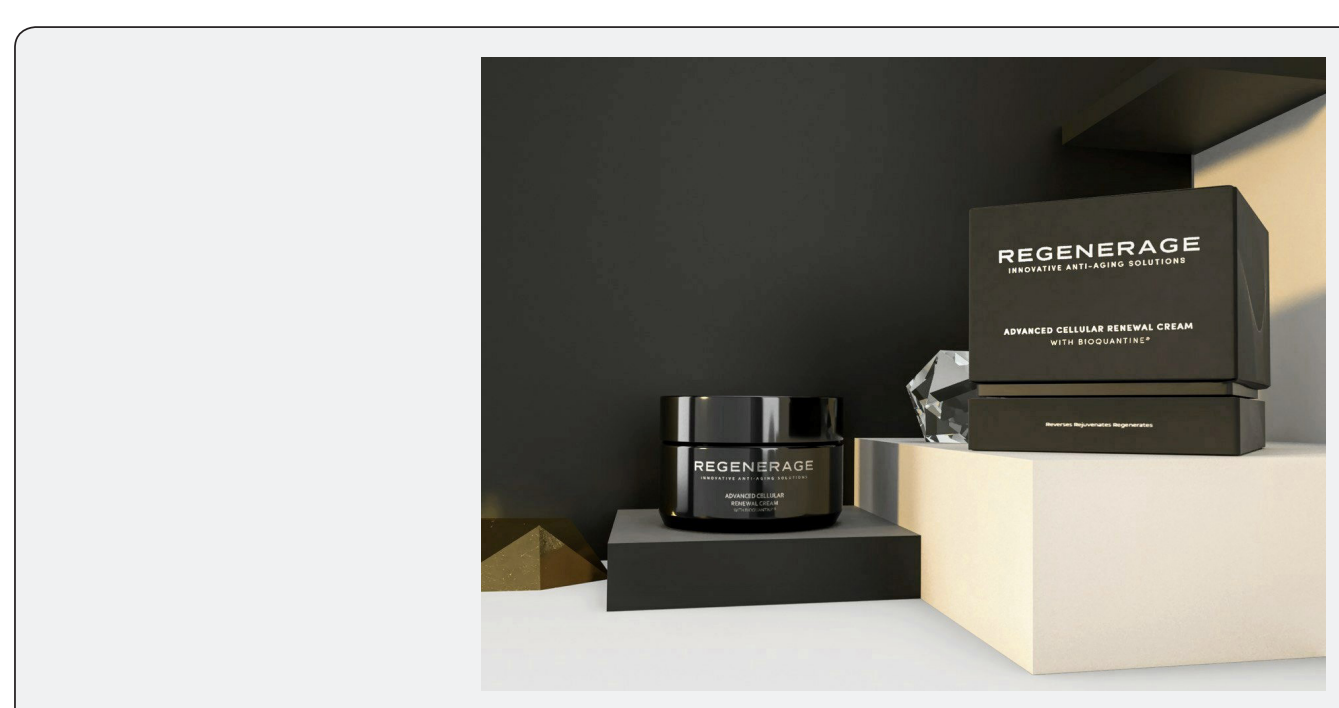

Figure 5:Regenerage original cream.

Table 2: Griffiths scale.

\begin{tabular}{|c|c|c|c|c|c|}
\hline & $\mathbf{0}$ & 1 & 2 & 3 & 4 \\
\hline Pores & Not visible & Slightly enlarged & $\begin{array}{c}\text { Moderately enlarged, } \\
\text { located }\end{array}$ & $\begin{array}{c}\text { Moderately enlarged, } \\
\text { large }\end{array}$ & $\begin{array}{l}\text { Markedly enlarged, } \\
\text { located }\end{array}$ \\
\hline Superficial Wrinkles & Not visible & Moderate & $\begin{array}{l}\text { Moderate, located in large } \\
\text { areas }\end{array}$ & Moderate, large areas & $\begin{array}{l}\text { Marked, located or } \\
\text { large areas" }\end{array}$ \\
\hline Deep Wrinkles & Not visible & Moderate & $\begin{array}{l}\text { Moderate, located in large } \\
\text { areas }\end{array}$ & Moderate, large areas & $\begin{array}{l}\text { Marked, located or } \\
\text { large areas }\end{array}$ \\
\hline Hyperpigmentation & $\begin{array}{l}\text { No hyperpigmen- } \\
\text { tation }\end{array}$ & $\begin{array}{l}\text { Light, small } \\
\text { areas }\end{array}$ & $\begin{array}{l}\text { Moderate, small areas or } \\
\text { light, moderate areas }\end{array}$ & $\begin{array}{l}\text { Moderate, moderate areas } \\
\text { or Light, large areas or } \\
\text { Marked, small areas. }\end{array}$ & $\begin{array}{c}\text { Marked, moderate or } \\
\text { large areas }\end{array}$ \\
\hline Erythema & Not visible & $\begin{array}{l}\text { Minimum - al- } \\
\text { most impercep- } \\
\text { tible }\end{array}$ & $\begin{array}{l}\text { Mild - predominantly min- } \\
\text { imal (pink colour) with or } \\
\text { without some isolated areas } \\
\text { of more intense erythema }\end{array}$ & $\begin{array}{l}\text { Moderate - predominantly } \\
\text { moderate (red) with or } \\
\text { without some isolated } \\
\text { areas of intense erythema } \\
\text { (bright red) }\end{array}$ & $\begin{array}{l}\text { Severe - predomi- } \\
\text { nantly and intensely } \\
\text { (bright red) with or } \\
\text { without some isolat- } \\
\text { ed areas (deep red) }\end{array}$ \\
\hline Dryness and scales & Not visible & $\begin{array}{l}\text { Minimum - Bare- } \\
\text { ly noticeable } \\
\text { peeling }\end{array}$ & $\begin{array}{l}\text { Light - Limited areas of fine } \\
\text { desquamation in up to } 1 / 3 \\
\text { of the area }\end{array}$ & $\begin{array}{l}\text { Moderate - Fine peeling } \\
\text { involving } 1 / 3 \text { to } 2 / 3 \text { of the } \\
\text { area or limited areas of } \\
\text { thicker scale. }\end{array}$ & $\begin{array}{c}\text { Severe - Involves } \\
\text { more than } 2 / 3 \text { of the } \\
\text { area or limited areas } \\
\text { of very thick scales }\end{array}$ \\
\hline
\end{tabular}




\section{Ethical Considerations}

i. This protocol was reviewed and evaluated in the methodological, scientific and ethical aspects, by the Research Ethics Committee and the Research Committee of the Jalisco Institute of Clinical Research S.A. of C.V.; which, granted the approval opinion, on July 9, 2019, with Folio number 1068, which was valid throughout the trial.

ii. The study was submitted to the Jalisco Ministry of Health and was verbally notified that by modification in the internal processes, folios of the State Research Registry are no longer granted to protocols that are not from a federal entity.

iii. In accordance with the Regulations of the General Law of Health in the Area of Health Research, Second Title, Chapter I, Article 17, was considered with a greater risk than the minimum [9].

iv. This protocol was conducted according to the regulations established in the Declaration of Helsinki $\left(59^{\text {th }}\right.$ General Assembly, Seoul, Korea, October 2008). It also adhered to the guidelines of Good Clinical Practices and the International Harmonization Conference on Technical Requirements for the Registration of Medicinal Products for Human Use.

v. The patients received standard medical care and in accordance with the Mexican Official Standard of Pharmacovigilance (NOM-220-SSA1-2012) there were no serious adverse events [6].

Overall objective: To evaluate the anti-aging effect of REGENERAGE $^{\circledR}$ cream in Mexican women.

\section{Specific objectives}

a. Determine on the face surface parameters of living skin (SELS, Surface Evaluation of Living Skin): superficial spots, wrinkles, texture, pore, UV spot, deep spot, red area and porphyrins with the use of REGENERAGE ${ }^{\circledR}$ cream in Mexican women.

b. Evaluate the aging parameters on the face with the Glogau and Griffiths scales with the use of REGENERAGE ${ }^{\circledR}$ cream in Mexican women.

c. Evaluate the signs and symptoms of irritation with the use of REGENERAGE ${ }^{\circledR}$ cream in Mexican women.

d. Evaluate the overall therapy satisfaction with the use of REGENERAGE $^{\circledR}$ cream in Mexican women.

e. Evaluate the safety by spontaneously reporting adverse events with the use of REGENERAGE ${ }^{\circledR}$ cream in Mexican women

Hypothesis: $H 1=$ REGENERAGE $^{\circledR}$ cream has an anti-aging effect in Mexican women.

Independent variables: Administration of REGENERAGE ${ }^{\circledR}$ cream or placebo.
Dependent Variables: Surface stains, wrinkles, texture, pore, UV spot, deep stain, red area, porphyrins, Glogau and Griffiths scales, irritation scale, adverse events, Global Satisfaction Therapy Scale (Researcher / Patient), adverse events.

Efficacy analysis: Efficacy was determined in the complete analysis set (per-protocol) of women, which is defined as all randomized patients. All results were analyzed according to the allocation of randomized study products.

Security analysis: Safety analysis was performed in all randomized patients who received $\geq 1$ dose of the researched product. For the safety analysis, patients were grouped according to the allocation of randomized study products.

Sample size: Because it is an exploratory study, no sample size calculation was performed. Randomization. The assignment of treatments was carried out by generating a random number table in Excel, specifying the number 1 as a lower rank, and the 12 as the top rank, group A and group B. Thus, each generated number was assigned one of the two treatments: 12 REGENERAGE $^{\circledR}$ and the following 12 to placebo. For each treatment, according to its random number, the code REG-n and legend "1-Right" "2-Left" was assigned.

Blinding: The study was conceived as double blind, in which neither the sub-investigator / clinical coordinator nor the patient knew which study product was being administered. The study products delivered had the same characteristics in any of the study groups and were labeled with the following information: Protocol identification number, Research Center, Identification code and sequential number, Date of Expiry.

Terms of use: The following legends: "External use on skin", "Sale is prohibited", "Exclusive use of clinical protocol patients", "Do not use in children or pregnant women", language in Spanish and Alert symbols or pictograms.

Effectiveness evaluation. Quantitative variables were expressed in average, median, standard deviation and ranges. Vital signs and anthropometric parameters were evaluated using parametric statistics with the T- Studen test to find differences between visits and groups. On the other hand, the response data were evaluated with non-parametric statistical tests. Analysis was performed with the Wilcoxon test to evaluate the differences between treatments over time. The Mann-Whitney $U$ test was used as post-hoc to evaluate the differences between the study groups. For qualitative variables, these were expressed in $\%$ and were compared by means of the Chi2 test. It was considered that there were significant differences when $\mathrm{p}<0.05$.

Safety assessment: The safety criteria that were evaluated to establish intra and/or differences between treatments are described below. Safety was evaluated by the clinical review of all relevant parameters, including adverse events, irritation parameters and vital signs. The number of cases that presented 
adverse events, the number of cases directly related to the study drugs, and the percentage of cases that resulted from these incidents were calculated. These frequencies were compared between treatments using the Chi test [2]. It was considered that there were significant differences when $\mathrm{p}<0.05$.

\section{Results}

Flow of participants: Fifteen women were invited to participate in the study. 5 were not included, because they did not comply whit the criteria. For the assignment of the study treatments, 10 women who comply whit the criteria were randomized and signed their informed consent. In this way, 10 treatments were applied in one side face and another 10 treatments in the opposite side face. There were no follow-up losses in any patient and the groups for the final analysis were distributed as follows: 10 REGENERAGE ${ }^{\circledR}$ treatments and 10 treatments to the placebo group.

Recruitment: First patient inclusion date: August 9, 2019 Last patient closing date: November 23, 2019.

Demographic characteristics: $100 \%(n=10)$ of the patients were women. The average age was $44 \pm 3.9$ years. The level of education was mostly bachelor's degree in $90 \%(n=9)$, followed by $10 \%$ high school $(n=1) .90 \%(n=10)$ of the patients were active workers with administrative activities and $10 \%(n=1)$ trader.

\section{Effectiveness}

Surface parameters of living skin: In the efficacy analysis performed for the face surface evaluation parameters for each of the study groups, the percentages of the baseline measurements were compared against the percentages of the final measurements and statistically significant differences were observed for both groups in the percentage of UV spots. On the other hand, when the percentages of the differences in the evaluations between the two groups were analyzed, no statistically significant differences were found between the study groups.

Glogau scale: Regarding the classification of facial aging with the Glogau scale, it was observed that at the beginning of the study, the majority of patients $70 \%(n=7)$ were classified as type III and the $30 \%(n=3)$ type II, keeping the same percentages at the end of the intervention.

Griffiths scale: In the clinical evaluations carried out with the Griffths scale, it was observed that the patients started with an overall score of $13.1 \pm 2.2$ and at the end of the intervention with $13.4 \pm 2.5, p=$ NS. The average scores for each of the parameters are broken down.

Irritation: In the phone calls of weeks 2 and 4, none of the patients reported manifesting any symptoms of irritation. For the visit of week 6, in 4 patients the presence of irritation symptoms was reported. In all cases the symptom was mild and did not merit the suspension of the study products.

Overall patient satisfaction: $50 \%(n=5)$ of the patients referred to the study products they received during the intervention as "good", $40 \%(n=4)$ as "very good" and a patient $10 \%$ described it as "excellent" (Figure 6).

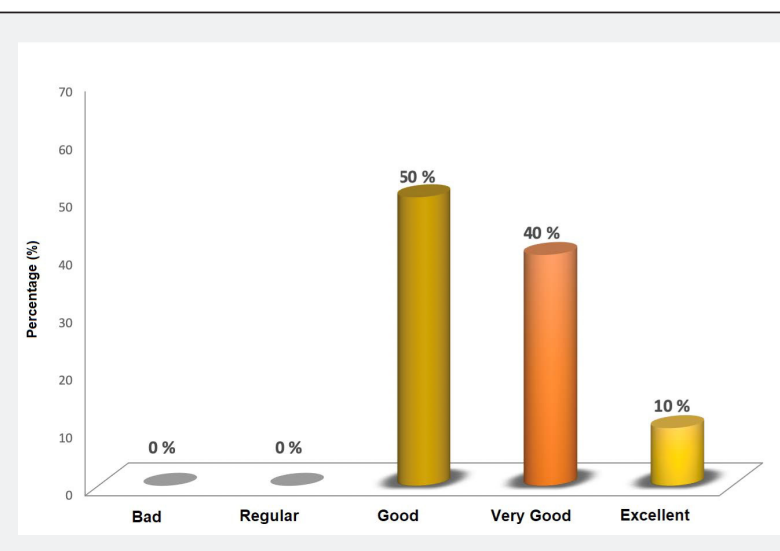

Figure 6:Global Satisfaction with Study Products - Patient.

Adverse events: There were no adverse events in the entire study. Likewise, the administration of concomitant therapy was not reported.

Adhesion to treatment: No deviation was presented with the study products. All patients complied. $>80 \%$ of the applications of the study products were made in 12 weeks.

\section{Conclusion}

a. Differences were observed at the end of the intervention with respect to baseline in both study groups, in the UV spot parameter; probably by the joint administration whit sunscreen.

b. In the parameters of the live skin surface, scales of Glogau, 
Griffiths and irritation, no statistically significant differences were observed between the groups.

c. The study patients and the sub-researcher felt satisfied with the study products.

The administration of REGENERAGE ${ }^{\circledR}$ cream on the face for 12 weeks proved to be a safe management of Mexican women.

\section{References}

1. Rodríguez-Cabrera A, Gálvez-González AM, Alvarez-Vázquez L (2019) Aspectos económicos del envejecimiento demográfico y su importancia para la toma de decisiones en el sector salud. El caso Cuba. INFODIR 15(28): 13-27.

2. Shah AR, Kennedy PM (2018) The aging face. Med Clin North Am 102(6): 1041-1054

3. Heilman M, Stopeck M (1985) Being attractive, advantage or disadvantage? Performance-based evaluations and recom- mended personnel acions as a function of appearance, sex, and job type. Organ Behav Hum Decis Process 35: 202-215.
4. Orozco-Ríos AM, López-Velarde Peña T, Martínez-Gallardo Prieto L (2015) Estrategias para un envejecimiento exitoso. Rev Esp Geriatr Gerontol 1-6.

5. McCook JP (2016) Topical products for the aging face. Clin Plast Surg 43(3): 597-604.

6. (2012) Norma Oficial Mexicana Nom-220-Ssa1-2012. Instalación y operación de la farmacovigilancia.

7. Tejero-García P, Zamorano-Triviño MV, García-Monforte F (2011) Análisis cualitativo y cuantitativo de las alteraciones cutáneas en el paciente de medicina estética. In: Tresguerres-Hernández J (Ed.), Medicina Estética y Atienvejecimiento. Madrid: Editorial Panamericana, p. 33-44.

8. Taub AF, Bucay V, Keller G, Williams J, Mehregan D (2018) Multicenter, double-blind, vehicle- controlled clinical trial of an alpha and beta defensin-containing anti-aging skin care regimen with clinical, histopathologic, immunohistochemical, photographic, and ultrasound evaluation. J Drugs Dermatol 17(4): 426-441.

9. Regulation of the General Health Law on Health Research (2019) Consulted, ICH Secretariat, Switzerland.

\section{Your next submission with Juniper Publishers will reach you the below assets}

